\title{
“DETALHES DE SUA INCOMPETÊNCIA NÃO ME INTERESSAM": O ASSÉDIO MORAL NO FILME O DIABO VESTE PRADA ${ }^{1}$
}

\author{
Helltonn Winicius Patricio Maciel ${ }^{2}$ \\ Diogo Henrique Helal ${ }^{3}$
}

http://dx.doi.org/10.1590/1413-2311.181.75135

\section{RESUMO}

Este caso aborda o assédio moral vivenciado em uma revista de moda de grande repercussão internacional. Revela as relações conflituosas de uma secretária recém-contratada com sua chefe e sua colega de trabalho em um contexto repleto de glamour, soberba e subserviência. Os diálogos expõem a supervalorização do trabalho perfeito, do comportamento narcísico e de intenções maldosas, repercutindo no dilema da secretária de permanecer ou não na revista.

Palavras-chave: Assédio Moral. Relações de Trabalho. Caso para Ensino. Filme.

\section{"DETAILS OF YOUR INCOMPETENCE DO NOT INTEREST ME": THE MORAL HARASSMENT IN THE MOVIE THE DEVIL WEARS PRADA}

\begin{abstract}
This case deals with moral harassment experienced in a great international fashion magazine. It reveals the conflicting relationships of a newly hired secretary with her boss and her coworker in a context filled with glamor, pride, and subservience. The dialogues expose the overvaluation of perfect work, narcissistic behavior and malicious intentions, reflecting the secretary's dilemma whether or not to stay in the magazine.
\end{abstract}

Keywords: Moral Harassment. Work relationships. Teaching Case. Movie.

\section{"DETALLES DE SU INCOMPETENCIA NO ME INTERESAN": EL ACOSO MORAL EN LA PELÍCULA EL DIABLO VISTE DE PRADA}

\section{RESUMEN}

Este caso aborda el acoso moral vivido en una revista de moda de gran repercusión internacional. Revela las relaciones conflictivas de una secretaria recién contratada con su jefe

\footnotetext{
${ }^{1}$ Recebido em 21/07/2017; aprovado em 26/07/2017.

${ }^{2}$ Instituto Federal de Educação, Ciência e Tecnologia da Paraíba - hw.campina @ gmail.com.

${ }^{3}$ Faculdade Boa Viagem - diogohh@yahoo.com.br.

REAd | Porto Alegre - Vol. 23 - No Especial - Dezembro 2017 - p. 412-427
} 
y su compañera de trabajo en un contexto repleto de glamour, soberbia y servidumbre. Los diálogos exponen la sobrevaloración del trabajo perfecto, del comportamiento narcisista y de intenciones malvadas, repercutiendo en el dilema de la secretaria de permanecer o no en la revista.

Palabras-clave: Acoso moral. Relaciones de trabajo. Caso de Enseñanza. Película.

\section{INTRODUÇÃO}

Mais um dia para se buscar um novo emprego. Andrea Sachs, 26 anos e jornalista de formação, está em busca de seu lugar ao sol no mercado profissional. Tendo um currículo atrativo em função dos muitos trabalhos jornalísticos já desenvolvidos, ela está ansiosa e esperançosa em conquistar sua primeira oportunidade de trabalho.

Naquela manhã de março que lhe parecia bastante promissora, a jovem adentra um dos arranha-céus na cidade de Nova York, o Elias-Clark. Lá, uma entrevista de emprego a espera.

Ao passar pelo setor de recursos humanos, ela é encaminhada para a revista Runway, uma das revistas mais famosas do mundo da moda, capitaneada por Miranda Priestly, cuja fama é maior que a própria revista pelo seu conhecimento sobre o mundo da moda, mas também pela sua personalidade forte e centralização do poder no cargo de diretora-chefe da empresa. Porém, (in)felizmente, tais informações não faziam parte do cotidiano de Andrea.

O local onde a edição da revista Runway funciona possui portas que se abrem silenciosamente, áreas impecavelmente brancas de recepção, móveis chiques, de linhas simples e limpas. O nome da revista encontra-se gravado nas paredes em tipologias cheias de estilo, de forma destacada. Portas de vidro espesso e opaco protegem os locais de trabalho.

Homens e mulheres esbeltos, de beleza clássica, parecem desfilar pelos locais de trabalho. Todos muito bem vestidos, com acessórios de alto padrão, como cintos, bolsas, sapatos, xales. Além disso, uma infinidade de outros artefatos indica o glamour de marcas famosas, como Prada, Gucci, Armani, Valentino, Versace... Tudo ali contrasta com a aparência, conteúdo e roupas que Andrea apresentava. Não que ela estivesse malvestida para um padrão de escritório. Todavia, o estilo básico não faz parte do repertório daquele ambiente.

Chegando no andar da revista, Andrea é recepcionada com sarcasmo por Emily, primeira assistente da Miranda Priestly, que não foge ao alto padrão com o qual Andrea já tinha se deparado. Emily afirma que há dias procura por alguém para o cargo de segunda assistente, já que as duas últimas candidatas à vaga foram demitidas em duas semanas pela 
própria Miranda. "Precisamos de alguém que sobreviva, está entendendo?”, afirma Emily. Andrea então pergunta: “Quem é Miranda?”.

Com um ar estupefato, Emily critica a candidata que desconhece um dos maiores ícones da moda. "Uma lenda!", afirma Emily, enfática, e continua: "Trabalhe para ela e conseguirá emprego em qualquer revista. Milhões de garotas se matariam por este trabalho!".

Andrea afirma que adoraria trabalhar ali, e Emily, olhando para a roupa que Andrea veste, diz com ar irônico: "Andrea, para trabalhar na Runway, gostar de moda é essencial”.

Neste momento, o celular da primeira assistente recebe uma nova mensagem contendo uma notícia terrível: o esteticista de Miranda tinha desmarcado, e ela estava retornando para a empresa. Rapidamente Emily liga para um outro ramal da empresa e pede para que avisem a todos: "Ela está chegando!".

Uma corrida frenética eclode em todos os setores da empresa, todos apressados para deixar tudo milimetricamente como a editora-chefe da revista exige: mesas limpas, roupas nas araras corretas, sapatos sofisticados nos pés, maquiagem sobriamente feita no rosto, água tônica, revistas devidamente posicionadas na mesa, tudo perfeito. Andrea, imóvel, apenas observa, silenciosamente, a afobação de todos.

Eis que Miranda chega no prédio da Elias-Clark. No trajeto da saída de sua limusine até a revista, ninguém fica à sua frente. Todos param, abrem as portas, saem do elevador para que todo o deslocamento da diretora seja feito sem interrupções, sem esperas desnecessárias. Ao chegar na revista, Miranda expressa sua insatisfação: "Eu não entendo como é tão difícil confirmar um compromisso."

Emily tenta se justificar, mas é interrompida: "Detalhes de sua incompetência não me interessam. Diga a Simone que não vou aprovar a garota que mandou para o layout brasileiro. Pedi clara, atlética e alegre e ela me mandou parda, cansada e gorda. E diga que vou à festa do Michel Kors, quero que o chofer me deixe às 21:30 e me pegue às 21:45 em ponto. Depois ligue para Natalie da Glorious Foods e diga que não, pela milésima vez, que não quero aquela sobremesa, quero tortas recheadas com compota quente de ruibarbo. Depois ligue para meu ex-marido e lembre-o da conferência à noite no Dalton. Depois ligue para meu marido e fale para me encontrar para jantar no lugar em que fui com Massimo. Avise a Richard que vi as figuras que mandou com as características das paraquedistas femininas e que não têm atrativo algum. É impossível achar uma paraquedista feminina agradável, magra? Exijo muito? Com certeza não. E preciso ver o que Nigel conseguiu para 
a segunda capa de Gwyneth. Eu adoraria se ela perdesse um pouco de peso. Quem é essa?" [Miranda se refere a Andrea ao passar rapidamente por ela, dirigindo-se a sua sala].

Emily diz que se trata de uma candidata ao cargo de assistente, mas que a mesma é inadequada. Miranda retruca e diz que ela mesma irá entrevistá-la, visto que as últimas duas não foram eficientes na função.

Emily então diz a Andrea que Miranda quer entrevistá-la. Seguindo para a sala de Miranda, Emily, de forma brusca, toma a maleta de Andrea e a joga para debaixo de uma mesa próxima dizendo que não leve "aquilo" para a sala da diretora-chefe por ser uma bolsa antiquada e fora dos altos padrões de moda ali exigidos.

Ao adentrar, Miranda pergunta quem é ela, e Andrea começa a se apresentar. Eis que a diretora faz os questionamentos: "Então você não lê a Runway? E até hoje você não ouviu falar sobre mim?”. Em seguida, afirma: “[...] E você não tem estilo e senso de moda”.

Andrea continua a falar de suas atribuições, quando é interrompida por Miranda, que encerra a entrevista: "É só isso".

Apesar de sair do escritório de Miranda sem nenhuma esperança de conseguir o emprego, Andrea se surpreende com a notícia de que foi contratada.

\section{O TRABALHO NA RUNWAY}

Às 6h16min do dia seguinte à entrevista, o telefone da casa de Andrea toca e, ao atender, ela é surpreendida por Emily do outro lado da linha, que já lhe fornece as primeiras instruções do dia: "Andrea, Miranda decidiu mudar a edição das jaquetas de outono de setembro e está preparando Sedona pra outubro. [Você] Precisa vir para o escritório agora e pegue o café dela no caminho. Pegue uma caneta e anote isso. Quero um expresso com leite, sem espuma e com café extra e três cafés para colocar leite. Muito quente, extremamente quente”.

Momentos depois, já no escritório, Miranda pergunta se a assistente morreu, pois até então o seu café não estava na mesa. Em seguida, Andrea chega no escritório e é advertida por Emily: "Espero que saiba que é um trabalho muito dificil para o qual você não serve. E se você estragar tudo, minha cabeça vai rolar. Anda, esconda isso! [Referindo-se ao casaco de Andrea] Não fique mostrando em todo lugar”.

Emily ainda diz para Andrea não sair da mesa, e que ela tem que atender ao telefone sempre que tocar. A segunda assistente pergunta a Emily o que fazer caso ela precise ir ao

REAd | Porto Alegre - Vol. 23 - No Especial - Dezembro 2017 - p. 412-427 
banheiro, e recebe a seguinte resposta: "Uma vez uma assistente saiu da mesa porque cortou a mão com o abridor de cartas e Miranda não conseguiu ligar para o Lagerfeld antes de voar por 17 horas para Austrália. Agora ela trabalha para o 'Guia de TV'”.

Emily continua as instruções para a segunda assistente: "Lembre-se, eu e você temos trabalhos totalmente diferentes. Quero dizer, você pega o café e busca as coisas na rua. Eu ainda controlo toda a agenda dela, os encontros dela e as despesas. E, o mais importante, eu irei para Paris junto dela para a Semana da Moda. Eu preciso usar uma roupa linda. Eu vou a todos os desfiles e festas. Eu conhecerei todos os estilistas e artistas famosos. É divino! Ok. Agora, fique aqui. Eu vou ao departamento de arte para entregar 'O Livro'. O livro é uma síntese de tudo que está sendo criado atualmente. E nós levamos ao apartamento de Miranda toda noite, e ela retorna. Não toque nisso. Ela devolve para nós de manhã com as anotações que ela fez. A segunda assistente é quem deveria fazer isso, mas Miranda é muito reservada e não gosta de estranhos em sua casa. Então, até ela ter certeza de que você não é uma psicopata, eu fico com a tarefa de cuidar do Livro”.

Emily então vai entregar o livro no departamento de arte. É quando Miranda chama por ela. Após chamar três vezes, Andrea surge na sala para atendê-la:

Miranda: "Ah, você está aí, Emily, quantas vezes eu tenho que gritar seu nome?”

Andrea: "Na verdade, me chamo Andy. Meu nome é Andy. Andrea, mas todos me chamam de Andy"

Miranda, expressando um leve desdém por ser surpreendida pela correção de Andrea: "Eu preciso de 10 ou 15 saias da Calvin Klein”.

Andrea: "Que tipo de saias?"

Miranda: "Por favor não me incomode com suas perguntas. E tenha certeza que teremos o Pier 59 às 8 h amanhã. Lembre Jocelyn que preciso ver algumas bolsas que Marc está fazendo no pônei. E depois fale para Simone que eu vou pegar o Jackie se Maggie não puder. O Demarchelier confirmou? Ligue para ele agora. E, Emily... [Miranda fita advertidamente as roupas que Andrea está usando] Isso é tudo”.

Ao correr para sua mesa, e sem saber por onde começar, Andrea é "salva” por Emily, que traz outras instruções para Andrea: "Miranda falou que tipo de saias?”, e antes que Andrea pudesse esclarecer ela continua: “Nunca pergunte nada para Miranda, entendeu?!'. Ainda diz para Andrea que ela deve ir pegar as bolsas. Antes que a recém-contratada pudesse perguntar outra coisa, Emily faz um questionamento: "Você já tem outro lugar para ir? Um desfile de saias ridículas que tenha que ir? [risos]".

REAd | Porto Alegre - Vol. 23 - No Especial - Dezembro 2017 - p. 412-427 
No caminho, Andrea recebe duas ligações quase que ao mesmo tempo, uma delas é da própria Miranda perguntando se ela já tinha chegado na Calvin Klein. Quando a assistente diz que não, sua chefe desliga rapidamente sem escutar os outros esclarecimentos que a jovem tinha a fazer. Em seguida, Emily liga atribuindo novas tarefas para Andrea: "Miranda precisa que você vá ao Hermès e pegue 25 cachecóis que pedimos para ela. Cassidy esqueceu o trabalho no Dalton. Vá lá e pegue. Miranda foi se encontrar com Meisel, e ela vai querer mais café da Starbucks quando voltar. Quentes." E antes que Andrea pudesse perguntar sobre a primeira tarefa, Emily desliga o telefone.

Ao retornar para o escritório, Emily pergunta a Andrea o porquê de ela ter demorado tanto, pois ela precisava ir ao banheiro. Nesse momento Miranda surge e, lança a sua bolsa e seu casaco sobre a mesa de Andrea. Hábito que ela repete inúmeras vezes no decorrer do filme, demonstrando superioridade e desprezo pelo espaço de trabalho das secretárias.

Dias depois, durante o expediente de trabalho, Emily explica para Andrea sobre os ensaios fotográficos, atividades que são desenvolvidas no escritório de Miranda. Neles, os editores trazem as opções para cada look a ser montado e Miranda define diversos detalhes. Isso demonstra o comportamento centralizador de Miranda em relação ao que é feito pelos funcionários.

Nesse momento, surge Serena, uma das colegas de trabalho de Emily. Andrea é apresentada a ela, que a observa um tanto espantada e diz para Emily: "Achei que você estivesse brincando". Ao sair com Emily para o almoço, Serena pergunta sussurrando: "Mas o que ela está usando?". Emily gargalha e diz em alto e bom som: "As saias da avó dela".

Após o horário de almoço de Emily, ocorre o tão importante ensaio fotográfico. Momentos depois dele, Miranda demonstra-se desapontada e aborrecida, afirmando que as roupas são mórbidas, confusas, e que ninguém está pronto, apesar das longas horas que tiveram para preparar o ensaio. Todos na sala demonstram tensão e preocupação. Andrea observa tudo na sala da diretora-chefe.

Observando uma das combinações de roupas, Miranda pede que uma das funcionárias lhe traga alguns cintos. Ao trazer as opções, a funcionária diz que se trata de uma escolha difícil, pois são muito diferentes. Andrea, ao ver as opções e ser leiga no assunto, acha graça e esboça um leve sorriso. Para ela, os cintos eram praticamente iguais.

Todos na sala percebem o sorriso dela, inclusive Miranda, que a pergunta enfaticamente a razão da graça. Andrea diz que ainda está aprendendo sobre essa "coisa". Ao ouvir isso, Miranda inicia um longo discurso persuasivo para a jovem contratada: "Acha que 
isso tudo aqui não tem nada a ver com você. Você vai até o seu guarda-roupas e você escolhe... não sei... essa blusa azul horrível, por exemplo, porque você está tentando dizer ao mundo que você se considera muito séria para se preocupar com o que se vestir. Mas o que você não sabe é que essa blusa não é apenas azul. Nem turquesa. Nem cor de céu. Na verdade é azul celeste, e você também não está ciente do fato de que, em 2002, Oscar de la Renta fez uma coleção de roupas de cor azul celeste. E depois Yves Saint Laurent criou as jaquetas militares de cor azul celeste. E depois, essa cor apareceu em coleções de oito estilistas diferentes. [...] Depois disso, chegou às lojas de departamentos...e depois acabou em liquidações em alguma lojinha de esquina onde você, sem dúvida, comprou sem nenhuma nota fiscal. De qualquer forma, esse azul representa milhões de dólares e trabalhos incontáveis, e é cômico que você tenha feito essa escolha achando que é exímia do mundo da moda quando, na verdade, você está usando uma blusa que foi escolhida para você por pessoas desta sala, de um monte de 'coisas'”.'

Andrea se sente injustiçada e humilhada por ter recebido um sermão por algo que ela entende como banal. Momentos depois, já em seu apartamento, ela desabafa com o seu namorado sobre o tal sermão, criticando a supervalorização de algo tão trivial: "Todos agem como se estivessem curando o câncer ou algo do tipo. A quantidade de tempo e energia que essas pessoas gastam em coisas insignificantes, detalhes, e para quê? Para amanhã elas poderem gastar mais US\$300 mil refazendo alguma coisa que provavelmente estava boa desde o começo para vender às pessoas coisas de que elas não precisam! [...] Sabe o quê? Só tenho que aguentar isso por um ano. [...] Mas não posso permitir que Miranda fique me humilhando."

Os dias se passam, as atribuições continuam intensas, consecutivas e confusas. As ordens de Miranda são as mais diversas possíveis, pouco explicadas, levando os funcionários a terem que se desdobrar para captar detalhes sem fazer qualquer tipo de questionamento. Todos os funcionários se mobilizam para atender às exigências de Miranda, inclusive Andrea, e ainda assim a chefe não se sente satisfeita, perguntando com bastante ironia se as pessoas realmente estavam trabalhando ali.

Certo dia, após uma rotina repleta de atividades do escritório, Andrea aproveita a chance de poder relaxar com o pai em um restaurante da cidade, já que Miranda encontrava-se em outra cidade resolvendo assuntos de negócios. Durante o jantar, o pai se preocupa com a situação da filha, dizendo que até ele recebe e-mails do escritório da Runway às duas horas da manhã, além de pagarem pouco para ela, e de ela não estar produzindo artigos de jornal. 
Andrea então pede para o pai ter paciência, pois trabalhar na Runway irá lhe abrir várias portas. No meio da conversa, Andrea recebe uma ligação de Miranda pedindo para que marque um voo.

O que Andrea não imaginava era que este telefonema lhe tomaria todo o tempo do seu jantar. Todas as tentativas de marcação de voo acabam sendo frustradas, até pelas péssimas condições climáticas que ocorriam na cidade onde Miranda estava, o que fez a diretora-chefe não perder apenas o voo como também o recital de suas filhas da escola, deixando-a furiosa.

Quando finalmente retorna para Nova York, ela adverte Andrea severamente: “ $O$ recital das garotas estava absolutamente maravilhoso. Elas tocaram Rachmaninoff. Todos amaram, menos eu porque, infelizmente, eu não estava lá. Você sabe por que eu te contratei? Eu sempre contrato a mesma garota, elegante, magra, claro! Que gostam da revista. Mas com o tempo, elas se tornam, eu não sei, decepcionantes e estúpidas. Então você aparece, com aquele currículo impressionante e com um discurso sobre essa sua tão falada 'ética de trabalho'...Eu... Eu achei que você seria diferente. Eu disse a mim mesma, 'vá em frente. Corra o risco. Contrate a garota inteligente e gorda'. Eu tinha esperanças, meu Deus, como eu tinha. De qualquer forma, você me decepcionou mais que qualquer... mais do que qualquer outra garota tola."

Andrea tenta se retratar dizendo: "Eu realmente fiz tudo que estava ao meu alcance". E Miranda responde: "Isso é tudo".

\section{A MUDANÇA DE ANDREA}

Após a advertência de Miranda, Andrea sente-se humilhada. Então ela conversa com Nigel, um dos diretores de arte da revista, e decide mudar radicalmente de postura na empresa, entregando-se totalmente ao padrão Runway de se vestir e de se portar. Com isso, ela passa a impressionar suas colegas de trabalho, inclusive Emily, que sente inveja. Até mesmo a própria Miranda percebe a mudança, limitando-se, contudo a olhares sutis de aprovação.

Com o passar dos dias, Andrea se adapta cada vez mais ao ambiente da revista, sobretudo ao linguajar cotidiano compartilhado pelos demais funcionários da empresa. As ligações de Miranda para Andrea se intensificam, sobretudo nos momentos em que ela está fora do ambiente de trabalho. A jovem passa a ser incumbida de atividades mais importantes, cumprindo-as eficientemente.

REAd | Porto Alegre - Vol. 23 - No Especial - Dezembro 2017 - p. 412-427 
Um detalhe importante é que, até aqui, pouco importava o nome de Andrea para Miranda, que sempre a tratava como Emily. Porém, essa situação muda a partir de um evento particular em que Andrea se antecipa a uma ordem de Miranda. Isso faz com que a jovem receba a incumbência de entregar o livro da revista na casa da própria Miranda Priestly.

Emily então faz todas as recomendações que Andrea deve seguir ao entrar na casa de Miranda: ela não devia ser notada por ninguém, e deixar o livro em um local específico. Todavia, ao chegar na casa da diretora da revista, Andrea percebe que as instruções de Emily não foram suficientemente claras, pois havia muitos locais semelhantes onde o livro poderia ficar. Nesta situação de grande aflição, Andrea é vista pelas filhas de Miranda, que a pedem para ficar com o livro. A assistente então vai ao encontro das meninas, porém, no caminho, Andrea presencia uma cena em que Miranda discute questões pessoais com o seu marido e sua presença acaba sendo notada por sua chefe, que lança um olhar fulminante sobre a jovem. Sem emitir um único som, Andrea apenas deixa o livro no chão e sai em arremetida.

No dia seguinte pela manhã, Emily conversa reservadamente com Andrea, e a adverte severamente, pois ela já tinha tomado ciência do grave erro que a segunda assistente cometeu na casa de Miranda. Emily diz: “Andrea, você não entende. Se for despedida, irá prejudicar minha ida a Paris. Se isso acontecer, vou procurar em todo lugar até te achar”. Andrea, assustada, pergunta: "Ela vai me demitir?”. E Emily responde: "Não sei. Ela não está feliz”.

Andrea então é chamada por sua chefe. Na sala de Miranda, Andrea tenta se desculpar pelo ocorrido, mas é interrompida pela chefe que delega à jovem uma nova tarefa: conseguir o manuscrito inédito do próximo livro do Harry Potter para suas filhas. O problema era que este livro sequer tinha sido publicado, estando em fase de formatação. Ao terminar de incumbir a tarefa desafiadora, Miranda diz: "Nós conhecemos todos do mundo editorial. Isso não seria um problema, seria? E você pode fazer qualquer coisa, não pode? Minhas meninas vão embarcar no trem para a casa da avó delas às 16h, então é bom que o livro esteja aqui até às 15h. E eu gostaria do meu filé aqui em 15 minutos".

Emily observa tudo e esboça uma feição de prazer ao ver as difíceis tarefas que Miranda exigiu de Andrea. A segunda assistente parte para o cumprimento das tarefas, a iniciar pelo filé. Apesar de o restaurante preferido de Miranda não estar aberto, ela acaba conseguindo o almoço da diretora-chefe. Esta, por sua vez, ao ver o almoço em sua mesa, diz que não vai comer aquilo e que sairia para almoçar fora. Antes de deixar a revista, ela fala em alto e bom som: "Gostaria que meu lanche da Starbucks estivesse aqui quando eu voltar. E se não estiver com o livro do Harry Potter até lá, não se preocupe em voltar”.

REAd | Porto Alegre - Vol. 23 - No Especial - Dezembro 2017 - p. 412-427 
Andrea liga freneticamente para diversos contatos que ela estabeleceu ao longo do tempo na revista Runway na tentativa de conseguir o manuscrito. A jovem começa a aceitar que será demitida, mas é neste momento que um de seus contatos retorna a ligação afirmando que conseguiu o manuscrito inédito. Andrea então respira aliviada por ter conseguido cumprir uma missão que ela já considerava perdida.

Ela retorna para a revista e entrega um exemplar do manuscrito em formato de livro para Miranda, dizendo que aquela era uma das três cópias que ela tinha feito, e que as outras duas já estavam com as filhas. A jovem pergunta a Miranda se ela teria mais algum pedido a fazer e, sem ter o que dizer, Miranda apenas diz: "É só isso".

No filme, não é apenas Andrea que sofre com a chefe; os demais funcionários também, apesar de toda a reverência e admiração que eles atribuem a Miranda. Em uma reunião sobre as novas temáticas a serem inseridas na revista, há o seguinte diálogo entre Miranda e equipe:

Miranda: "Não... Está bem, fevereiro é o assunto. Alguém já falou com o pessoal de Salma?"

Funcionária A: "Sim, mas ela prefere fazer um ensaio no verão porque ela está fazendo um filme...”

Miranda: "Não [interrompendo]. Também estou colocando as peças do Toobin nas mulheres da Suprema Corte... E eu preciso ver um novo desenho dessa coleção sobre cirurgia plástica... Está chata! E esse esboço para o 'Inverno no paraíso' ainda não está maravilhoso.

Funcionário B: Ok. Vou ver isso."

Miranda: "E quanto a Testino? Como estamos?”

Nigel: "Zac Posen está fazendo alguns ternos esculturais. Então eu sugiro que Testino lance-os no Jardim Noguchi”

Miranda: "Perfeito. Graças a Deus alguém veio trabalhar hoje. E sobre os acessórios para Abril?"

Funcionária A: "Eu pensei em adornos. Como, pulseiras, pingentes, brincos..."

Miranda: "Não [interrompendo]. Nós usamos isso há dois anos atrás. Que mais?"

Funcionário A: “Eles estão mostrando vários arranjos florais no momento, então eu pensei..."

Miranda: "Flores? Para a primavera? Que inusitado!"

Funcionário B: “Mas pensamos em usá-los em um local industrial. Pensamos no

REAd | Porto Alegre - Vol. 23 - No Especial - Dezembro 2017 - p. 412-427 
contraste entre o feminino das flores...e aquela paisagem precária poderia criar uma maravilhosa tensão..."

Miranda: “Não”.

A festa beneficente de Miranda está para acontecer. O problema é que Emily adquire um forte resfriado devido a sua baixa imunidade, já que ela mal tem se alimentado para poder vestir as marcas famosas que a revista proporciona. Ao perceber a situação de Emily, Miranda designa que Andrea também a acompanhe na festa. Todavia, tal atividade não corresponde apenas em se fazer presente. As assistentes precisam informar a Miranda, de forma bastante discreta, quem são os convidados da festa antes mesmo que eles se aproximem da diretora. Andrea então terá poucas horas para memorizar duas pastas repletas de informações das celebridades que participarão da festa. Durante o evento, Emily esquece as informações de um dos convidados. É quando Andrea informa a Miranda de quem se trata, demonstrando sua capacidade à chefe. É a partir daí que Andrea começa a se destacar no trabalho, inclusive conseguindo atender às exigências de proatividade, ou seja, conseguindo a proeza de se antecipar aos pedidos de sua chefe, algo que até então só tinha sido alcançado por Nigel, um funcionário mais antigo na revista que sempre se identificou com o universo da moda.

Os dias se passam, mais um final de expediente chega, e Andrea vai até a casa de Miranda deixar o livro da revista, desta vez, no local correto. É quando ela escuta a voz de Miranda chamando seu nome. A jovem vai ao encontro de sua chefe, que diz: "Paris é a semana mais importante do ano todo. Eu preciso da melhor equipe comigo. E isso não inclui Emily”. Andrea diz, surpresa: “Espere. Você quer que eu...não, Miranda. Emily poderia morrer. A vida toda dela é sobre Paris. Ela não come há semanas. Eu não posso fazer isso. Miranda, não posso”. E Miranda encerra: “Se você não fizer, vou dizer a todos que você não é apta para a Runway ou qualquer outra revista. A decisão é sua. É só isso”.

Andrea sai da casa de Miranda bastante reflexiva. Ela não poderia desistir naquele momento, estava tendo um excelente desempenho na revista. No dia seguinte, ela chega mais cedo ao escritório. Miranda surge e, em vez de entregar sua bolsa e casaco para Andrea, ela joga tais peças na mesa vazia de Emily, e ainda pede a Andrea para ligar naquele momento para Emily informando a decisão. A jovem faz o que lhe é mandado. Contudo, nos primeiros segundos de conversa com Emily pelo telefone, Andrea escuta um forte impacto. Emily acabara de se acidentar na rua e é levada para o hospital.

Andrea vai visitar Emily no hospital e diz que decidiu ir com Miranda para Paris, se justificando dizendo que não teve escolha. Emily não aceita e diz que Andrea vendeu sua 
alma no primeiro instante em que colocou um par de sapatos de uma marca famosa e a expulsa do quarto do hospital.

Andrea sai se sentindo triste com a situação. Sua vida pessoal também está bastante abalada de tanto se doar para o seu trabalho, pois, por causa dele, ela está se afastando de seus amigos e de seu namorado. Entretanto, estes sentimentos temporariamente adormecem quando Andrea chega a Paris. O esplendor e glamour da semana de moda a deixam maravilhada.

A campainha toca no quarto do hotel onde Andrea está hospedada. É Nigel, um dos funcionários mais antigos da Runway. Ele pede o itinerário de Miranda do dia seguinte e diz a Andrea que está muito feliz, pois em breve será sócio de um estilista de renome internacional, James Rolt. Os dois celebram esta iminente conquista.

No fim deste mesmo dia, Andrea se encontra com o contato pessoal que a forneceu o manuscrito do Harry Potter, e acaba tendo um caso amoroso com ele. No dia seguinte, ela descobre por este contato pessoal que Miranda será destituída do seu cargo e que a arquirrival dela, Jaqueline Follet, da filial da Runway francesa, ficará em seu lugar. Andrea então vai ao encontro de Miranda para tentar avisá-la que existia uma conspiração contra a diretora-chefe.

Não sabia Andrea que Miranda já tinha se antecipado. Em uma reunião secreta com o dono da Elias-Clark, organização a qual a revista Runway é subordinada, ela entrega uma lista de fotógrafos, maquiadores, estilistas e diversos outros profissionais que a seguiriam para onde quer que ela fosse caso fosse destituída do cargo na revista. Vislumbrando uma forte possibilidade de crise na revista, o dono da Elias Clark decide não demitir Miranda, e ela, sem hesitar, indica o nome de Jaqueline, sua arquirrival, para a sociedade com o estilista James Rolt no lugar de Nigel.

Chegado o dia mais importante do evento em Paris, onde estão reunidos diversos profissionais da moda, inclusive Miranda, Jaqueline, Andrea e Nigel, Miranda comunica a todos que Jaqueline será a sócia de James Rolt. Todos ficam surpresos com a decisão. Andrea sente-se revoltada por Miranda não ter deixado a sociedade com Nigel.

Horas depois, Miranda e Andrea seguem para outro evento em uma limusine e estabelecem o seguinte diálogo:

Andrea: "Eu não poderia fazer o que você fez com o Nigel, Miranda, eu não faria isso"

Miranda: "Mas você já fez.....com a Emily"

Andrea: "Mas aquilo...foi diferente, eu não tive escolha"

REAd | Porto Alegre - Vol. 23 - No Especial - Dezembro 2017 - p. 412-427 
Miranda: "Não, não, você escolheu. Escolheu seguir em frente. Se quiser essa vida, essas escolhas são necessárias"

Andrea: "Mas e se eu não quiser isso? E se eu não quiser viver como você vive?"

Miranda: "Não seja ridícula, Andrea. Todo mundo quer isso, todos querem ser como somos."

Após este diálogo, Andrea se depara com um dilema: aceitar ou não a visão de mundo de Miranda? Apesar de se defender da acusação da chefe, e independente de ela ter tido escolha ou não, Andrea sabia que tinha agido de forma semelhante com Emily. Aceitar a visão de Miranda poderia envolver Andrea ainda mais na revista e, quem sabe, torná-la realmente parecida com Miranda, algo que ela não almejava, sobretudo pelo seu desejo de atuar em outro segmento, o do jornalismo.

Andrea ainda não tinha um ano de experiência na Runway. Sair da revista de forma prematura poderia prejudicar o alcance de seu verdadeiro sonho. Ela está prestes a tomar uma decisão crucial sobre isto...

\section{NOTAS DE ENSINO}

\subsection{OBJETIVOS DE ENSINO}

- Identificar circunstâncias organizacionais que caracterizam o assédio moral;

- Refletir criticamente sobre tais práticas no ambiente de trabalho: causas e consequências.

\subsection{FONTE DE OBTENÇÃO DOS DADOS}

Filme O Diabo Veste Prada. Dirigido por David Frankel. O filme estreou no cinema em 2006, e foi indicado ao Oscar no ano de 2007 nas categorias de melhor atriz e melhor figurino. Apesar de não ter levado a estatueta do Oscar, o filme ganhou outras premiações: Globo de ouro de melhor filme, melhor atriz (Meryl Streep no papel de Miranda) e melhor atriz coadjuvante (Emily Blunt no papel de Emily).

\subsection{POSSÍVEIS TAREFAS A PROPOR AOS ALUNOS}

REAd | Porto Alegre - Vol. 23 - No Especial - Dezembro 2017 - p. 412-427 
Questões para discussão:

(1) Observando o caso, sobretudo os diálogos apresentados, indique: quais tipos de assédio moral podem ser observados?

(2) Quais comportamentos assimétricos mais comuns de assédio moral estão presentes nas cenas?

(3) Por que estas situações de assédio moral acontecem? Quais as possíveis consequências para os sujeitos e para a sociedade?

(4) Supondo que você estivesse no lugar de Andrea Sanchs, você escolheria permanecer na empresa ou sair dela?

\subsection{POSSÍVEL ORGANIZAÇÃO DA AULA PARA O CURSO}

Caso o(a) professor(a) disponha de software de edição de filmes, sugere-se o recorte das cenas específicas para exposição em sala de aula concomitante à discussão das cenas. $\mathrm{O}$ (a) professor(a) ainda poderá:

(a) delegar ao aluno(a) a leitura e análise individuais em casa ou na sala de aula;

(b) analisar e discussão dos alunos em pequenos grupos; e

(c) discutir em sessão plenária, orquestrada pelo professor.

Espera-se que professor e alunos possam discutir criticamente as políticas de gestão em grandes empresas encaradas como "modelos" de administração a serem seguidos e, desta forma, possam repensar tais práticas e se realmente vale a pena replicá-las no contexto de trabalho.

\subsection{APONTAMENTOS PARA AS RESPOSTAS DAS QUESTÕES}

- Questões 1 e 2

Podem ser observados os três tipos de assédio moral: horizontal, vertical e misto (MACHADO; IPIRANGA; MATOS, 2012; PESSOA, 2010 apud LIMA et al., 2014). As relações de Andrea com Emily, que ocupam a mesma função (ambas secretárias), são conflituosas. A todo momento, Emily denigre as funções de Andrea e delega atividades confusas e imprecisas, o que, de acordo com Barreto (2003), é uma forma de assédio.

Além disso, Emily ridiculariza Andrea para outras colegas de trabalho por meio de “abusos narcíseos" (ENRIQUEZ,2000 apud MACHADO; IPIRANGA; MATOS, 2012), como também ameaça Andrea se ela não desempenhar bem suas funções. A jovem contratada

REAd | Porto Alegre - Vol. 23 - No Especial - Dezembro 2017 - p. 412-427 
ainda sofre com os olhares e comentários ácidos e intenções maldosas (HELOANI, 2004 apud MACHADO; IPIRANGA; MATOS, 2012) de sua chefe Miranda, que sempre menospreza as atitudes de Andrea.

Os comportamentos assimétricos são notórios nas falas das personagens: "detalhes de sua incompetência não me interessam", "não precisa voltar", "é só isso", "não me incomode com suas perguntas", além das expressões que denotam desdém, ironia e soberba, geralmente pronunciados por Miranda. Comportamentos assimétricos são entendidos como aqueles que são desproporcionais na relação superior-subordinado. Referem-se a ações, gestos abusivos de pessoas que ocupam funções superiores em relação às demais pessoas.

- Questão 3

Aqui se abre um leque de possibilidades para a discussão em sala. Temas como a instrumentalização das relações de poder (PAGÉS et al., 1993), sofrimento, cultura organizacional autoritária (MOTA; CALDAS, 1997), e comportamentos antiéticos, são assuntos que podem ser correlatos na elaboração desta resposta.

A instrumentalização de poder refere-se à redução do ser humano a uma condição de objeto, de inferiorização, de coisificação, em que as pessoas são consideradas meras peças que podem ser facilmente manipuladas e descartadas nas corporações. No filme, pode-se perceber exemplos deste fenômeno quando, por exemplo, Miranda lança sua bolsa e casaco sobre o computador de suas assistentes, quando ela agride verbalmente seus funcionários: "Detalhes de sua incompetência não me interessam", "Por que ninguém está pronto?" "Onde está a nova assistente? Ela morreu?"

Como consequência dessa situação de assédio, pode ser explorada a questão da "liberdade de escolha", em que as alternativas são imperativas, demonstrando a limitação imposta pelo sistema socioeconômico (DEBORD, 1997 apud CARRIERI; AGUIAR; DINIZ, 2013). O caso ainda pode levar a conclusões de que o trabalho pode se tornar uma perigosa força de destruição da democracia e de difusão do cinismo e do individualismo (DEJOURS, 2007). No filme, percebe-se a ditadura coorporativa na forma como Miranda gerencia a empresa: o não questionamento, a supremacia, a reverência e o temor provocado nos seus subordinados nos mostra a passividade e a docilidade impostas sobre os trabalhadores. Além disso, é notória a dissimulação com a qual Miranda trata Nigel, um de seus melhores funcionários, e a falsidade que usa para tratar pessoas de alto nível hierárquico na empresa e na sociedade.

REAd | Porto Alegre - Vol. 23 - No Especial - Dezembro 2017 - p. 412-427 
- Questão 4

Permanecer ou não na revista poderá levar a consequências positivas e negativas. Cabe ao professor e à turma refletirem sobre quais as possíveis mudanças. É interessante levar em consideração que, permanecendo na revista, o sujeito continuará ampliando sua rede de contatos e tendo a estima por parte de Miranda, porém haverá o risco de haver distorções de valores. Pensar de forma semelhante à chefe da revista é a melhor forma de encarar o ambiente de trabalho em uma empresa?

Por outro lado, sair prematuramente da revista, ou seja, antes de completar pelo menos um ano de experiência, poderá dificultar o alcance do real desejo de trabalhar na organização almejada. Vale a pena o risco de manter seus valores e não atingir o seu real objetivo? (No caso de Andrea, o seu verdadeiro objetivo era trabalhar em um jornal de grande repercussão em Nova York, já que ela tinha estudado quatro anos para este fim).

\section{SUGESTÕES DE REFERÊNCIAS}

BARRETO, M. Violência, saúde e trabalho: uma jornada de humilhações. São Paulo: EDUC, 2003.

CARRIERI, A. P.; AGUIAR, A. R. C.; DINIZ, A. P.R. Reflexões sobre o indivíduo desejante e o sofrimento no trabalho: o assédio moral, a violência simbólica e o movimento homossexual. Cadernos EBAPE.BR (FGV), v. 11, N. 1, p. 165-180, 2013. DEJOURS, C. A banalização da injustiça social. Rio de Janeiro: Editora da FGV, 2007. LIMA, B. A. A. C. et al. Reflexões sobre assédio moral: um estudo à luz da organização pessoense com maior incidência em ações trabalhistas entre 2008 e 2012. Revista Gestão \& Tecnologia, v. 14, n. 1, p. 201-224, 2014.

MACHADO, D.; IPIRANGA, A. S. R.; MATOS, F. R. N. Quero matar meu chefe: retaliação e ações de assédio moral. Pretexto, Belo Horizonte, v. 14, n. 1, p. 52-70, 2013.

PAGÈS, M. et al. O poder das organizações. São Paulo: Atlas, 1993.

THE DEVIL wears Prada. Direção: David Frankel. USA, França: Fox 2000 Pictures, 2006. 